\title{
Bench for Vibration Study in an Unbalanced Motor Using
} Arduino

\author{
Thayanne Barros Bandeira ${ }^{1}$, André Souza da Cruz $^{1}$ and Wellington Fonseca da Silva ${ }^{2}$ \\ 1. Faculdade de Engenharia Elétrica, Universidade Federal do Pará, Campus Tucuruí, Tucuruí 68464-000, Brazil \\ 2. Faculdade de Ciência e Tecnologia, Universidade Federal do Pará, Campus Ananindeua, Ananindeua 67020-000, Brazil
}

Received: January 03, 2015 / Accepted: January 19, 2015 / Published: February 25, 2015.

\begin{abstract}
Part of the difficulty in engineering education is to achieve aggregate theoretical knowledge to practice what therefore discourages the student. Trying to alleviate this difficulty, practical problems are created to encourage students to apply their knowledge in different ways; these problems can be computational order, resolved by programs through simulation, or physical, with the realization of models, prototypes, benches or interactive platforms with visual practical approach. From this, it was proposed to students of the Federal University of Pará-Campus Tucuruí through the Electric Power Systems and Mechanics Research Group, in order to apply knowledge arising from multidisciplinary fields of engineering in the construction of a prototype with reused materials and low cost enabling studies and analysis of vibrations in unbalanced motors. This system features an open source prototyping embedded platform Arduino to read values from the sensors used: accelerometers and potentiometers coupled to the engine, aiming to collect values and vary the supply voltage. The results are read by Arduino and computationally processed to be printed on an LCD display. Therefore, the aim of this is to provide an accessible way using simple techniques a prototype linking the theoretical and practical knowledge as the system of the bench that performs vibration analysis in an unbalanced motor interactively, and encourage research and development technologies in the Amazon region.
\end{abstract}

Key words: Arduino, engineering, engines, vibrations.

\section{Introduction}

The origin of the vibration theory, historically, is the ancient Greek philosophers of the first millennium BC. The evolution of vibration theory has contributed to advances in basic sciences such as mathematics and general mechanics [1].

According to Afonso [2], much of human action involves some form of vibration ranging from the proper functioning of your body in breathing, hearing and heart rate to the most diverse areas of knowledge as well as biology, chemistry, physics and technology. In technology, the study of vibrations for modern engineering has important applications in machine design, structures, engines, control systems and other issues that require the vibrations to be taken into

Corresponding author: Thayanne Barros Bandeira, degree,
research field: thayane.bandeira@hotmail.com. account [3].

In engineering, vibration studies began motivated by the balancing problem in engines. The imbalance can be arising from both manufacturing as maintenance, since they are subject to vibration. Vibration analysis in machinery and equipment allows knowing them, improving them and gaining a lot in quality, productivity and development. Therefore, one of the important purposes of the vibration study is to achieve a reduction in vibration levels.

The study of vibrations is part of the probity of the curriculum of many engineers. During the graduation, these concepts are disciplined in class comprising the calculations/vibration equations and practice in laboratories where there is the completion of knowledge through the benchers and equipments. However, currently the interaction between theory and practice is still quite divergent due to the high cost of 
equipment making the extracurricular student access in public laboratories limited or even in some cases nonexistent. The lack of dialogue between theory and practice is undesirable because the experimentation interrelates the learner trial and the objects of their knowledge, theory and practice, that is, joining the interpretation of the subject to natural phenomena and processes observed, guided not only by scientific knowledge already established, but the knowledge and hypotheses raised by students, before challenging situations [4]. According to Freire [5], to understand a theory, it is necessary to experience it.

Conducting experiments is an excellent tool for the student to make the trial of the content and can establish the inseparable dynamic relationship between theory and practice. Practical classes can assist in the development of scientific concepts and allow students to approach objectively the world and develop solutions to complex problems [6].

The important thing is that in addition to motivation and verification of the theory, these classes are located in a historical and technological context related learning content, so that empirical knowledge is tested and argued, to finally happen to the construction of ideas, allowing students to manipulate objects, expand their ideas, negotiate meanings with each other and with the teacher during class [7]. For Vasconcelos et al. [8], the practical approach beyond their disciplinary relevance has deep social significance.

Following the ideas of these thinkers, there is the importance of developing practical activities that encourage students to build and enhance knowledge acquired in the classroom. Based on this, reasoning was offered to the students from the Federal University of Pará-Campus Tucuruí University through the Electric Power Systems and Mechanics Research Group, to apply their knowledge in the development of prototypes that unifies the theoretical and practical knowledge. Given this objective, in order to provide an accessible way using simple, low-cost techniques, and encourage research and technology development in the
Amazon region, this paper elucidates on the development of the system of a bench built for study and vibrations analysis in unbalanced motors using vibration sensors and the Arduino prototyping platform applying interactive methods. The paper is organized as follows: Section 2 discusses methodology; Section 3 presents results and discussions; finally, Section 4 gives conclusions.

\section{Methodology}

\subsection{The Functioning of the Bench}

The construction of the bench for vibrations study and analysis in unbalanced motors was proposed for the discipline of physics in order to make interaction practice with theoretical knowledge of important content in the discourse of engineering course.

To understand the functioning of the equipment, it is necessary to understand some basic concepts, e.g., when a force acting on an object causes displacement of the same regarding its idle shaft reaching maximum and minimum levels, in relation to their inertial point being described sinusoidally which is known as amplitude, the amount of time which is accomplished full movement in a given time is named vibration frequency and it is generally measured in hertz. It also vibrates at a certain speed if variable assumes an acceleration of the movement featuring an oscillating system. In the case of the bench consisting of an AC motor with unbalanced shaft suspended by a spring and its reasoned movements according to the vibrational assignments, the vibration frequency varies depending on engine speed and unbalance of its rotor.

The bench includes the interest to analyze/study the vibration in the engine representing a real progress in the implementation of a periodic external force whose intensity indicates the forced harmonic motion visibly demonstrating the vibration performed by the engine during the operation of the excitation force, responsible for maintaining the system "constant” oscillatory motion. During the oscillatory period, the vibration demonstrated on the spring is visible in two axes. 
However, in this work, we will consider only the vibration in the horizontal axis that we will represent through the $y$-axis, that axis vibration is the agent responsible for moving the spring in two ways: up and down with respect to the axis perpendicular to the base of the bench.

This system also has an embedded prototyping platform open source Arduino to read values from the sensors used: accelerometer and pot, coupled to the engine in order to collect values with the voltage variation. Subsequently to that collection, the values are treated through a computer processing done by the microcontroller to extract the acceleration, and then are sent to an LCD display in real time.

\subsection{Materials Used}

The use of low cost reusable materials is an option to encourage the build of copies or other prototypes that reduce the existing split in universities in relation to the link between theory and the actual interaction. Based on this concept, the following materials for the construction of the bench were used:

- iron reused from old gates used as the basis for the bench;

- polystyrene acquired from gifts factory;

- motor reused AC hoods;

- $12 \mathrm{~cm}$ of steel compression spring;

- reused helix TV antennas;

- Arduino platform;

- accelerometer sensor IMU 6DF;

- LCD display;

- dimmer;

- breadboard;

- jumper wires;

- electrical tape.

\subsection{The Bench Assembly}

The assembly of the bench is simple and with easy steps. Firstly, it is necessary to assemble the media on which the engine is suspended, setting four iron bars with $30 \mathrm{~cm}$ forming a square that will be the base system, then, joining two bars of $35 \mathrm{~cm}$ and a $30 \mathrm{~cm}$ forming a vertical rectangle with the base, as shown in Figs. 1-3.

Next, the polystyrene box is assembled following the iron support measures to protect those handling and those who observe the system in operation.

The next step was to couple the torsion spring $12 \mathrm{~cm}$ upper part of the support and suspend the next engine $0.786 \mathrm{~kg}$ holding it to the spring depicted in Fig. 4.

Once the motor-spring scheme is assembled, a reused TV antenna helix is inserted and the weight to

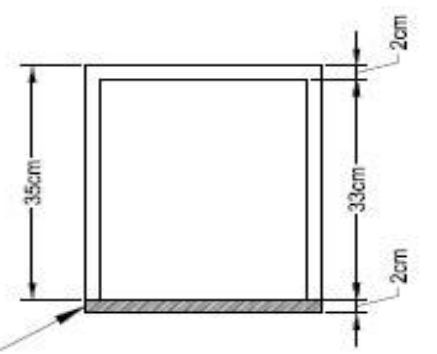

Fig. 1 Front view of the iron base.

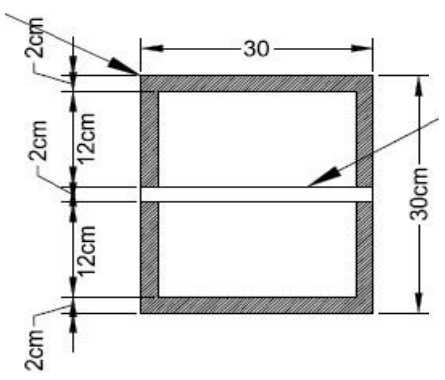

Fig. 2 Superior view of the iron base.

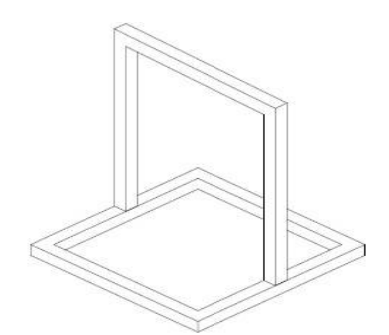

Fig. 3 Perspective of the iron base.

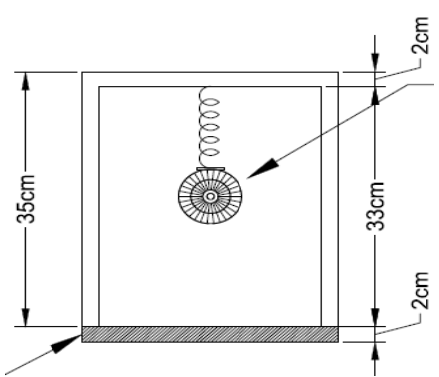

Fig. 4 Front view of the spring and motor coupled to the iron base. 
be used on the end of it is verified for performing the unbalance shaft reaching the desired vibration levels, for that the electrical tape was used, as we could go adding to the desired weight. The weight obtained by adding electrical tape was $0.05 \mathrm{~kg}$. Fig. 4 depicts the helix coupled to the motor.

After the mechanical system was assembled, we moved to the circuit assembly installing the accelerometer sensor on the engine and the Arduino microcontroller platform circuit in order to read the collected values and process the data in computer form and finally send them to the LCD display provisions of the breadboard. As we can see, Fig. 6 shows the accelerometer securely fastened to the engine and Fig. 7 represents the Arduino microcontroller circuit.

Fig. 8 configures the system's full bench, the completion of the mounting system.

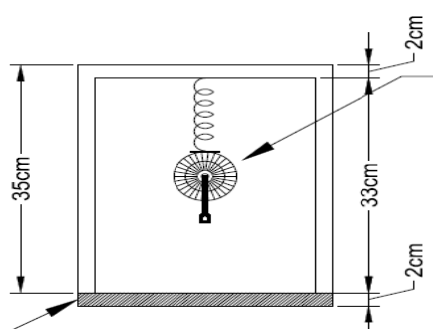

Fig. 5 Front view of the system partially done.

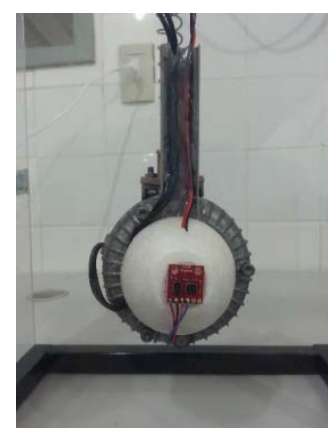

Fig. 6 Accelerometer coupled to the motor.

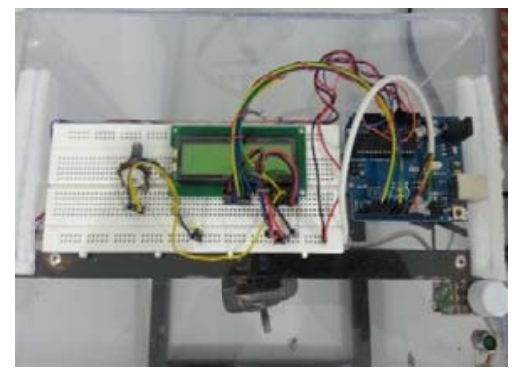

Fig. 7 Arduino-display circuit.

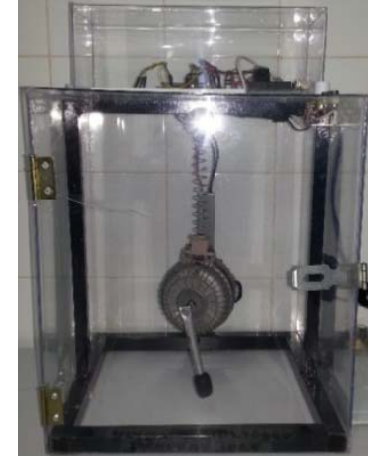

Fig. 8 Final bench system.

\section{Results and Discussions}

The approach of this experiment was directed to students of undergraduate university in electrical engineering in the period of the discipline of physics II.

The bench harmonized with interactivity concepts acquired in the classroom with the notion of reality.

By powering the Arduino microcontroller with direct current, it automatically activates the accelerometer, starts performing the vibration acceleration readings on the y-axis, sends the data to the display, and activates a light emitting as shown in Fig. 9.

As seen, the acceleration was approximately 10, which means that the engine is stopped, so the accelerometer is just reading the acceleration of gravity and the motor Arduino which reads these data and kindles the yellow LED indicates that the engine is stabilized.

In Figs. 10 and 11, we can observe the engine with $100 \%$ of its functioning, thus its vibration is constantly changing and it is transferred to the spring. The colors

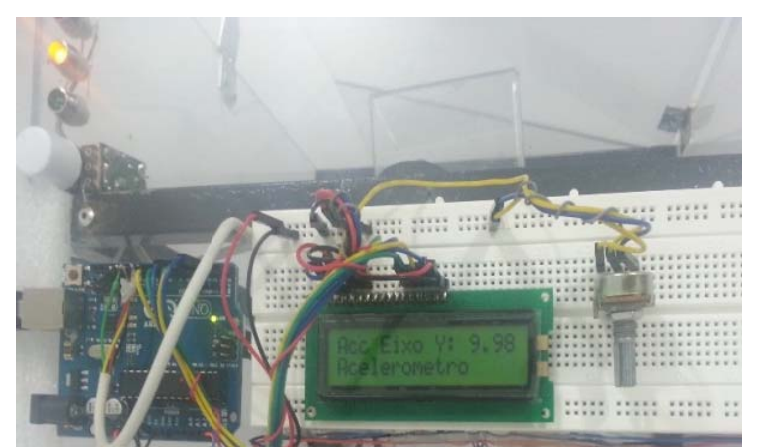

Fig. 9 Printed acceleration data in the display and yellow LED powered by Arduino. 


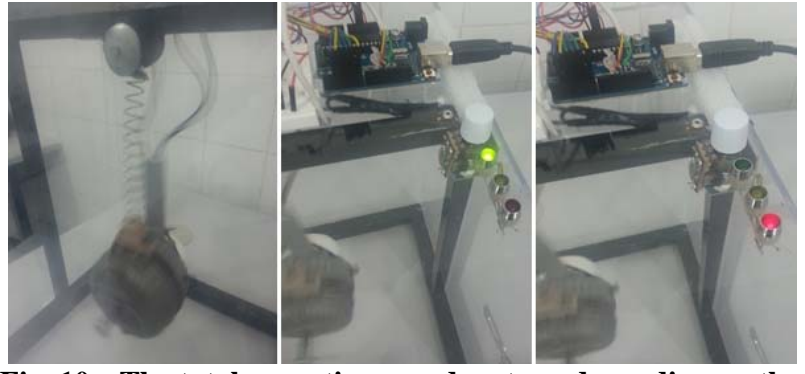

Fig. 10 The total operating speed system, depending on the vibration direction the Arduino drives a green or red LED.

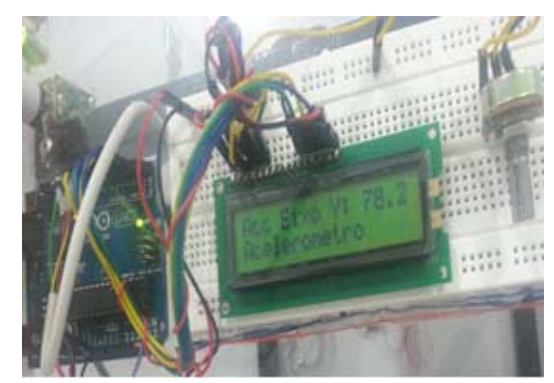

Fig. 11 The vibration value collected by the accelerometer $100 \%$ speed.

of the LEDs vary according to the displacement in y-axis. Green indicates the upper direction and the red the inferior one.

However, besides demonstrating interactively vibration performed by the motor when it has its unbalanced rotation axis, the bench also makes it possible to obtain data through the Arduino microcontroller, which is inserted in Eq. (1). It enables the production of specific graphics, as listed in Figs. 12-14.

$$
\ddot{x}+\frac{c}{m} \dot{x}+\frac{k}{m} x=\frac{F_{0}}{m} \sin \omega t
$$

\section{Conclusions}

The use of experiments/prototypes and the proposal of students to make them, to engineering education, creates a new possibility of learning to create a differentiated process that merely contact with the theoretical content of the subject and without interdependence with reality.

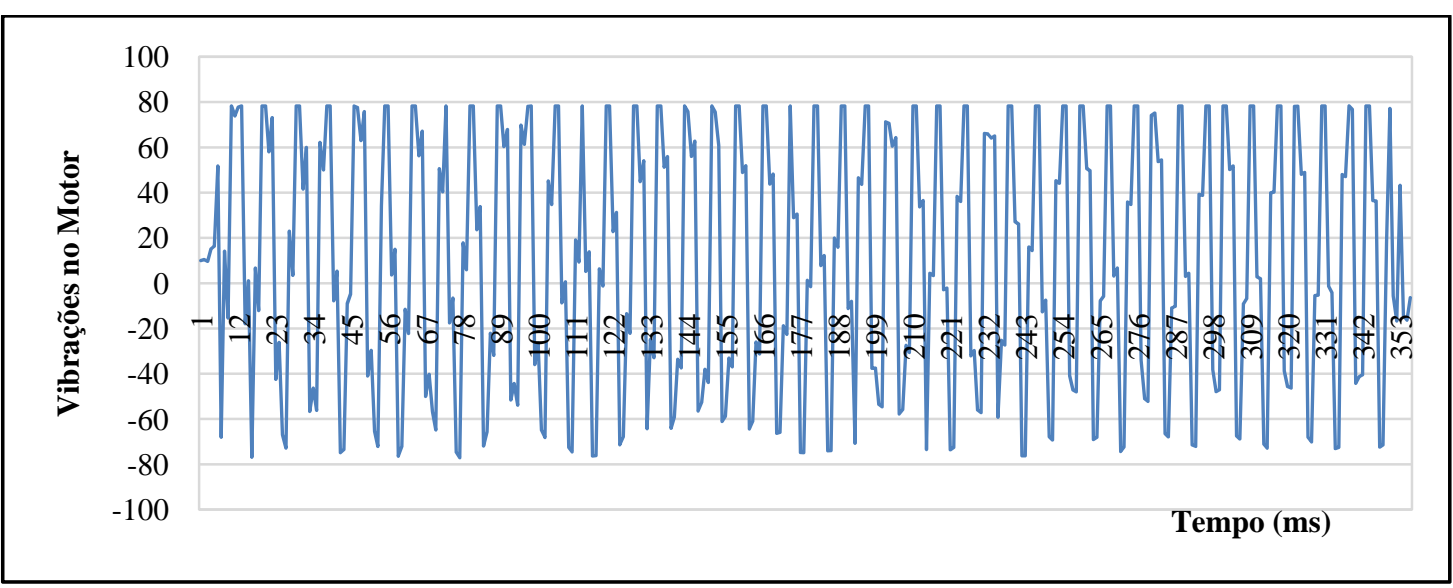

Fig. 12 Representative graphic of vibrations from the Arduino values acquired when the motor was $100 \%$ of its recorded speed.

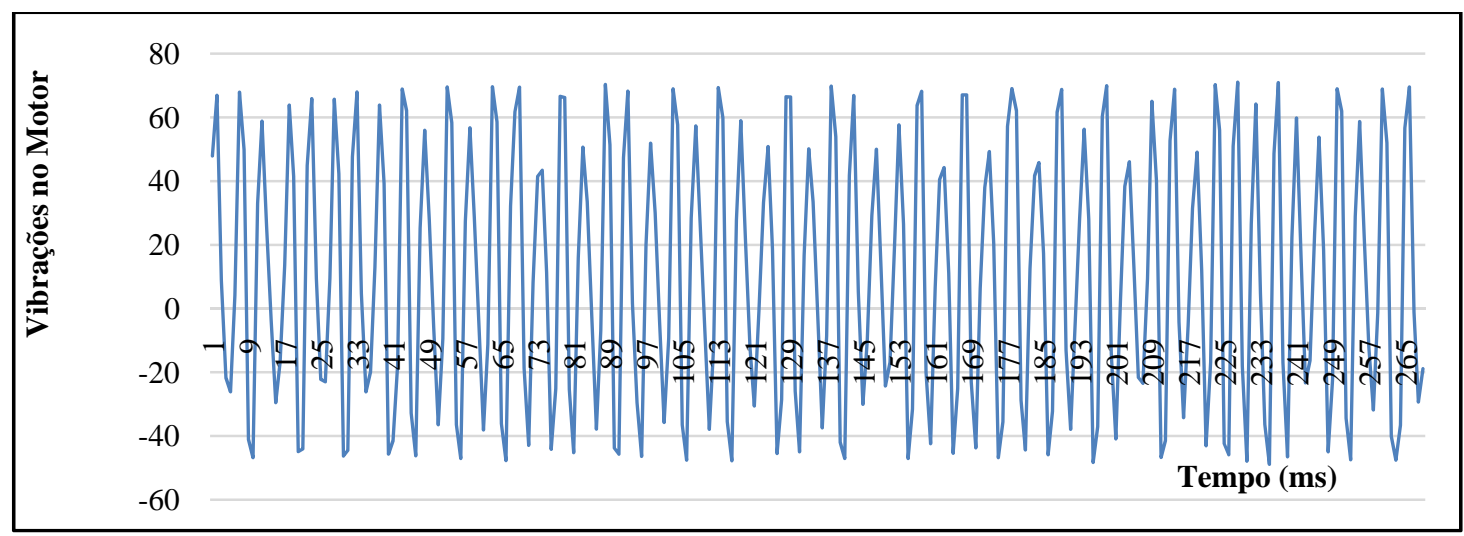

Fig. 13 Representative chart of vibrations from securities purchased Arduino when the engine was $50 \%$ of its recorded speed. 


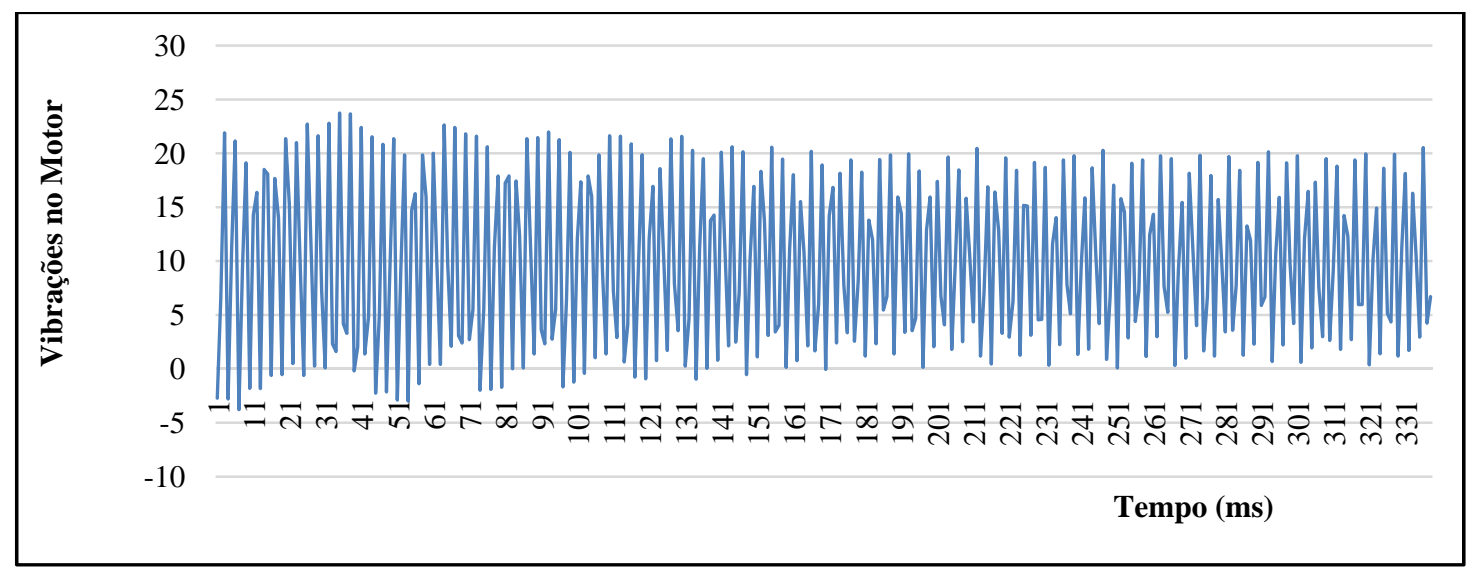

Fig. 14 Representative figure of vibrations from the Arduino values acquired when the engine was $10 \%$ of its recorded speed.

Thus, the bench for vibration study in an unbalanced motor using Arduino is shown interactively, an interesting learning tool in engineering education, by its simple construction and implementation, to be a work with low-cost materials, which allows the students to apply and understand most of the concepts related to vibrations, Hooke's law among others. So, this prototype becomes a great motivator time to learn and develop knowledge, and encourage more research and activities with this line in the Amazon region.

\section{References}

[1] Soeiro, N. S. 2009. Analysis Course of Noise and Vibration. Specialization Course in Engineering and Work Safety, UFPA, Belém.

[2] Afonso, E. 2012. "Effects of Vibrations on Health and Safety of Workers.” Access February 20, 2012. http://www.4work.pt/cms/indexphp?id=98\&no_cache=1 \&tx_ttnews\%5Btt_news\%5D=133\&tx_ttnews\%5BbackP id\%5D=100\&cHash=6b648f5780.
[3] Bsoeiro, N. S. 2008. Fundamentals Course of Vibration and Balancing Rotors. Belém: UFPA-Eletronorte.

[4] Lima, M. E. C. C., Júnior, O. G. A., and Braga, S. A. M. 1999. Learning Science-A World of Materials. Belo Horizonte: UFMG (Federal University of Minas Gerais).

[5] Freire, P. 1997. Pedagogy of Autonomy. Rio de Janeiro: Peace and Earth.

[6] Lunetta, V. N. 1991. "Practical Activities in the Learning of Cience.” Portuguese Magazine of Education 2 (1): 81-90.

[7] Gazola, R. J. C. 2011. "The Investigative Experiment and the Representations of High School Students as a Teaching Resource for the Survey and Analysis of Epistemological Obstacles.” Presented at the Regional Meeting South Biology Teaching, Londrina, Brazil.

[8] Vasconcelos, A. L. S., Costa, C. H. C., Santana. J. R., and Ceccatto, V. M. 2002. Importância da abordagem prática no Ensino de Biologia para a Formação de Professores (Licenciatura Plena em Ciências / Habilitação em Biologia/Química - UECE) em Limoeiro do Norte [Practical approach Importance at Biology Education for Teacher Training (Full Degree in Science / specialization in Biology / Chemistry - UECE) in North Lemon Tree]. 